\title{
Serious Games in Adaptive Learning
}

\author{
Aso Mohammad Darwesh \\ University of Human Development, Sulaimani, KRG, Iraq \\ Department of Information Technology \\ aso.darwesh@uhd.edu.iq \\ ORCID: http://orcid.org/0000-0002-4993-9786
}

\begin{abstract}
Most of educational institutions follow classical method of teaching that means same curriculum for all learners in the same order. But new generations look for a system of learning that adapts to his/her personal capacity. Adaptive education or adaptive learning is such a solution which can organize the content of the learning system based on learner's profile. This process is not simple, especially without using new technologies. Implementing adaptive learning in schools is very expensive. One of the digital techniques used in eLearning is by games. Games which are used for education more than entertainment are serious games. Games are the most famous and effective tools used in education because of the popularity of many kind of game devices and applications. In this paper we try to explain how serious games can be used in adaptive education. We also explore a new idea of using time in adaptive mechanisms. Adapting the content of learning based on multiple criteria not just learners' answers. Wrong answers does not always means inability to do things, or not understanding. Also, this may be due to lack of time or unfamiliarity with the device. This paper will also attempt to uncover the reasons for such delays and thus help us to better design an adaptive game.
\end{abstract}

Index Terms: Adaptive Learning, Educational System, Serious Game.

\section{INTRODUCTION}

Today's generation use many kinds of digital devices and have most opportunity to access different digital resources. They cannot continue learning in the same style as their grandparents. Forcing them to learn all curriculum by the same order defined by the pedagogues and in the same way as their grandparents cannot support new concepts such as 'student centered learning' and the recent global phenomena of 'self learning'. We need to think about a convenient alternative. This shift from content-based instruction to 'Blended Learning' makes the use of 'serious games' something not just worth venturing into but also a prerequisite for school systems worldwide [2].

Traditional school learning which is based on predefined sequential curricula cannot meet the requirements of children in the 21th century and on wards. In previous centuries, children began learning as they entered schools and only mastered the skills of reading and writing after progressing through the elementary stages. Today's children enter the school and they are almost capable of reading simple words and sentences, and similarly with writing. They are, commonly now, users of electronic devices before the age of school. The combination of education with entertainment increases learner motivation through increasing learner engagement [8]. Most of the time children use electronic devices to play games [1]. Without them being aware that this game helps them to learn something. Players can learn from usual games during gaming, because a game is composed of stories, scenarios, characters, environments and some other elements. Most of characters speak during gaming which helps player learn words said by that avatar. And if there are some sentences written on some boards inside the environment of the game, the player try to read it or to read it by the avatar if possible. In all cases if $s / h e$ knows that $\mathrm{s} / \mathrm{he}$ has to understand the sentence $\mathrm{s} / \mathrm{he}$ tries to learn it, because without it s/he cannot go to the next step. If there are some sentences difficult for the player, s/he does an action randomly.

The new generations of learners are surrounded by a huge array of electronic devices. Facility to have a smart device and be familiar to use such devices is changing the world of education. It is possible now to talk about going towards paperless education around the world. Today, learners' needs have changed. Users do not like that all of them follow the same linear curricula as in classical systems. Passive learning has expired and tutors must adapt themselves to the new systems of education. Learners must involve the learning process with better mastering of the information. This process is not easy even it is simple; Paramythis and Reisinger mentioned that "Adaptive learning systems endeavor to transform the learner from passive receptor of 
information to collaborator in the educational process" [13]. The process needs to allow for a better understanding of the basics and methodology by tutors. At the same time, applying adaptive learning is not possible in any learning system without using new technologies, because it is very time consuming and very expensive economically. Games are one of those applications that are used by very large percentage of electronic device users. Games play an important role in the learning process. Researchers try to adapt these games to teach players some notion because creating a good serious game is very expensive [3]. Adaptive learning adapts the content of learning or the curriculum to the level of learner. The aim of changes in the content of a game may be for the use of different pedagogues or different techniques by using different technologies [6]. It is simpler to use a game in adaptive learning than other applications, because games have basic educational elements like (curriculum, steps ...etc), by adapting the educational content based on learner's profile.

By thinking of serious games there are some question come to mind and must be answered. Does a modern learner accept to follow all the same curriculum? Shall we expect that schools can continue in the same style of last centuries? Can modern style schools be recognized or accepted easily? Does the order of curriculum assume importance to be followed by all learners? In this paper we try to find some answers for all these questions.

Educators design the curriculum to be taught sequentially to acquire definite set of outcomes related to specific syllabus. To learn a specific topic some steps must be followed by learner, but when outcomes are attained, is there any need to complete all steps as designed? That means is it possible to adapt the educational content to learners' capacity? Games, as one of e-learning techniques, can be composed of some basic elements among which is curriculum. Therefore, adapting learning content in games is an easy way of adaptive learning. Looking in details in both learning process and game process there are many common features between them. Despite the difference between each of the educational and learning process. As mentioned before in learning systems, learners follow some steps to learn the predefined fixed syllabus, and in these steps there are explanations by tutors, examples, self training him/herself, homework and finally there are exams to define learner's level of competence. In a game hints or feedback can help player learn some topics and gaming at the same time is learning and an 419 evaluation process. Because gaming is doing some actions and within each action, player has to think carefully about his/her decision and the result of these actions. When player passes some steps in one level and wants to reach a higher level s/he has to have acquired some skills and shown them, i.e., passes an exam. At the end of each level if all requirements of that level are achieved, i.e. the exam is passed, the player then goes to the next level.

After passing each level, all skills accumulate by the player are collected by the game which then can be used to determine what will be the next level. Is it the same predefined to all usual players or a specific one convenient to the capacity acquired in previous level? If the next step is a complement of previous to reinforce the skills of the player or the answers (actions) of the player showed that s/he does not need any more exercise on this topic, the system will suggest a different new level to test a new topic. Especially when the player passes a level in very short time, even sometimes less than what was expected by game designers. This means that if the system detects that any player has enough level of competence on any subject s/he can continue with a harder level. Knowing that; contents of low levels are always repeated in higher level steps implicitly (figure 1).

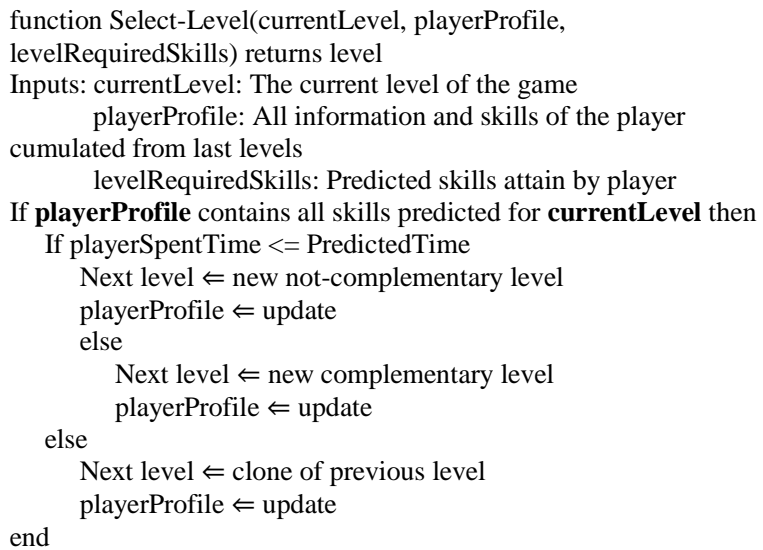

Figure 1: Our adaptive mechanism algorithm

Pedagogues with game designers define various set of steps of different exemplar players. But it is not possible to predict steps for all kind of players [5]. Instead a mechanism can be implemented to dynamically suggest new steps for players according to the collected answers. 


\section{ADAPTIVE GAME APPROACHES}

Some approaches have been proposed to create an adaptive game based on player's flow of experience [10], difficulty of the game faced by the player [12], player's frustration and avatar's health [14] and game play schemas [9]. Also some techniques which are used in this regard (Hendrix et al) suggest a model of integrating serious games into Adaptive Hypermedia [3]. The most important points that must be taken into consideration are; i) Design the game depend on the play testing. ii) The algorithm must tweak the game design without informing the player. ii) Adapting the game for all players is a very time consuming and may be impossible. Another problem that faced designer of serious game is the way to measure player's frustration because it needs some medical measurements like blood pressure, heart rate and conductivity [14]. Even though these approaches use different techniques, not all of them are implemented at this time because of complexity of the mechanism. On the other hand, a mixed approach of above solutions has been tested in one such instance [5]. Their idea is to merge feedback based on Dynamic Difficulty Adaptation as well as player's performance and adaptive flow. The approach has been implemented on a simple prototype and the result was promising.

Players learn by confronting problems in virtual life and attempt to find solutions. Failing is a part of the learning process, because it is there where learners try to understand and look at these problems more thoroughly. Although not all learners have the same style of learning, some of them are happy to make errors and try to find solutions, while others prefer to learn the topic at first then try them [15]. It may have immediate feedback for players on a specific situation or after completing one step to help understand what s/he can do and how it can be done. Player's enjoyment is linked to the appropriate level of difficulty. The player must fail and success in order to enjoy the game [7]. The game is not done to success every time, a game is a game, so must fail sometimes to understand how to fix or solve the issue. The same idea as learning inside a class, students try to learn what the reason of failing was.

In this paper we try to talk about another parameter which could be integrated with any of the mentioned approaches and can also be used to measure player's hesitation during gaming which is the time element. Player hesitates during gaming, especially when they are in a group or they have a competition. This situation of 420 the player can be measured using time spent for each action in a game. Usually the content of the game or the scenario is designed to be finished in a specific period of time. When someone takes more time, there are some reasons that would explain why this happened. The first one is the condition in which s/he the player is in, may be s/he is busy at that moment of the game and that will be the time of some actions; s/he could be late but not because of problems about how to decide. This situation could be found easily when it arrives one time, but the rest of the game player has no problem and finishes all steps in a given time period. The second reason is the intelligence degree of the player; sometimes a player is capable to pass some steps quickly but in some steps take much more time. This may be because of the step or level difficulty. This kind of situation can be determined on the progress made towards some levels. But to find out and distinguish exactly these causes, the complete profile of the player must be revised. The third reason of delay is related to the age of the player. Teenagers can play quickly, but children and older persons may be not as quick as required. Especially in serious games, they may not have any information about the topic and want to learn for the first time. If a player is slow from the beginning of the game, it is an indication to be categorized in the third category of players. Another reason for delay players meet in some steps is because of frustration. In the case of playing in a group or in competitions, even very intelligent players make some errors where s/he does not do it when s/he plays just for fun. Each player may have been frustrated one time when the game progress towards achievement is delayed or when the player cannot complete an action [5] [14].

To determine these situations some basic information must be registered by the game. For example, age of player, start time and date, place of gaming (school, home ...etc.) kind of playing (personal time spend, competition, group, inside class...etc.).

Managing time is very important in designing a game. Learners do not like spent time twice to acquire the same skill. If tutors give same copies of examples and exercises to improve learner's capacity, game designers must avoid this method and use different techniques instead like a different environment or a different scenario. This does not mean to never allow reinforcing important skills asked by educators. On the other hand, time can be an important parameter in adaptive learning. In the design step of the game curriculum, we can predict the time needed for answering any question. This 
parameter will be the key with some other parameters like the difficulty of the question, level of the question, game level...etc. to determine the next level of the game. When the player passes all steps successfully and very quickly, this means that this player does not need any other exercise on the curriculum of that level and can go to the next level without hesitation. But if the player passes successfully but did take more time than what was predicted for that step, this means that the player is not totally ready to go to the next step [table 1].

\begin{tabular}{|c|c|c|c|c|c|c|c|c|}
\hline \multirow[b]{2}{*}{ 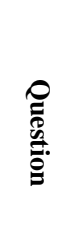 } & \multicolumn{5}{|c|}{ Capacities } & \multirow{2}{*}{ 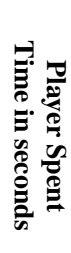 } & \multirow{2}{*}{ 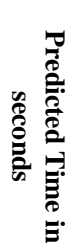 } & \multirow[b]{2}{*}{$\frac{\Omega}{\tilde{\theta}}$} \\
\hline & 1 & 1 & 1 & 1 & 1 & & & \\
\hline 1101 & 1 & 1 & 0 & 0 & 0 & 13 & 13 & 1101 \\
\hline 1101 & 1 & 1 & 1 & 1 & 1 & 9 & 13 & 1102 \\
\hline 1101 & 1 & 1 & 1 & 1 & 1 & 17 & 13 & 1101 \\
\hline 1101 & 1 & 0 & 0 & 1 & 1 & 13 & 13 & 1101 \\
\hline
\end{tabular}

Table 1: Adaptive mechanism table for same question answered by different users

But because in the game it is not possible to repeat a successful step twice, it must implement another instance of the same level curriculum in a different scenario. This process is not simple and very time consuming.

Hamadaoui et al [7] suggest using IMS-LD (The IMS Learning Design is a meta-language, developed by the Open University of the Netherlands, used to describe the main elements of the learning design process [16]) in the design of the educational serious game to facilitate the design process and enhance the learning objectives. This integration also helps the adaptation of the educational content to the profile of the learner.

The adaptive mechanism is 'middle ware' between the game and the player. And by using IMS-LD educators can interact with game designers to guarantee the right development of the game. The adaptive mechanism we propose suggests different levels for different players have same profile but with different time spent for previous level (figure 2).

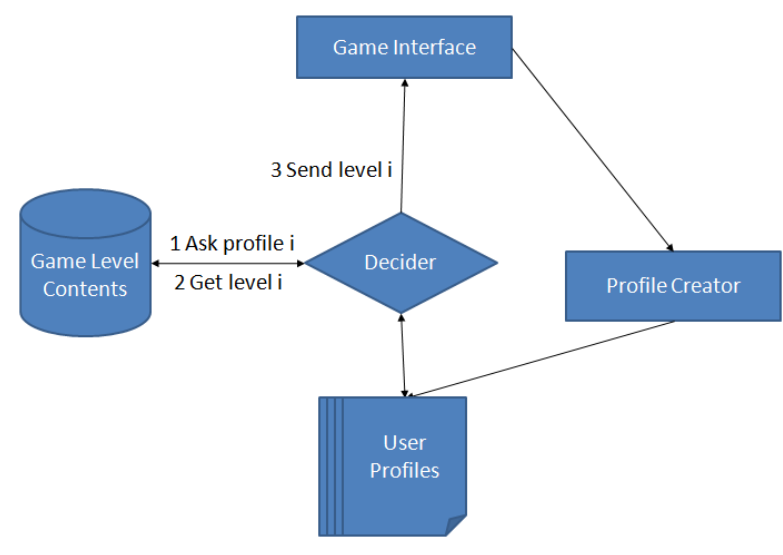

Figure 2: Adaptive mechanism flow of work

It is not important for the order of the curriculum to be the same for all learners; the aim of learning process is to achieve learning outcomes. If a learner can attain those outcomes expected by pedagogues there is no need to continue on that curriculum. And it is possible to achieve same outcomes by different learner following the same curriculum, as their intelligence levels are different. In addition, some notions repeat at different level. For example in language learning, letter recognition will repeat in writing complex words. If a player learns how to write a letter, the game can go through this step and suggest another kind of exercise.

\section{FUTURE OF LEARNING SYSTEM}

During the history of development of learning techniques, schools also evolved. Today's new technologies facilitate learning process more than any other time. But, unfortunately, we can say that the education field is the poorest field which benefits from these new technologies compared to other fields. It is not surprising if we say that if we bring back teachers of nineteenth century they don't have many problems teaching in today's classes, but it could be very difficult for doctors of the same era to work in today's hospitals. While doctors learn in the same classrooms as teachers, schools structures change very slowly. This is because new style classrooms cannot be recognized easily. Especially in undeveloped countries. Nevertheless in our century life is not simple; people have no more time to spend in learning fundamentals. Learning process in general must be changed. In the future, classical school system will be expensive for the lack of students who can go to those schools. Games as a very common and 
favorable learning tool will evolve quickly. Time will also be a very important parameter in the lives of new generations. We have to create models of learning that could be very simple and quick; so that learners can learn what they want in a very short time and with the best methods. In this step the very important point to be taken into consideration is the social relations between learners and tutors. Of course, there certainly has to be a kind of social medium between people, but not exactly as their parents'. That's what we have to expect by the time everything will be changed. And these changes are important for continuation of society. And discover what was not yet found. Despite everything, new generations will have more knowledge than older ones, because by using new techniques and new technologies, they can learn same topics in a very short time leaving them to learn more about other topics or skills.

Changing school structure may cause many discussions, but will be absolutely necessary to do some changes. Today schools advance little towards e-Learning, and using other speed learning processes. What concern eLearning is especially important at University level. And the conditions of speed learning are not easy to allow everybody to go to those schools. If we imagine to have spent about $25 \%$ of our lives to get a diploma, there is no guarantee that new generations can accept the same levels. New school structures, we may imagine, will be schools that students can select what, where and how s/he wants to learn.

\section{CONCLUSION}

In this paper we tried to explain adaptive learning using serious games. Some approaches have been described quickly and our contribution to a new approach has been detailed. Games as very famous and favorable learning tools would be used by learners of the Twenty First Century. Designers of serious games have to collaborate with pedagogues. Video game companies also must cooperate with researchers of serious games if they want to go through serious games development and implementation. While it is not necessary for a serious game to be a video game, but effectively video games are more attractive and emotionally appealing for learning environments. Adaptive learning would be inevitable in the upcoming years. The evolution of technology affects all dimensions of our lives. Education, as a major part of human life, must profit the maximum from these developments. It is very time 422 consuming, and very expensive, but a worthwhile investment in the abilities and skills of future generations. We predict that the current concepts of learning will change and the order of predefined curriculum has no more importance as in previous decades. Children will learn much even before starting school. Learning centers will be a place to learn some topics that help learners continue his/her career by him or herself.

In this regard, we tried to incorporate time parameter in adaptive learning mechanisms to maximize outcome of that concept. We think that learners spend less time to do a step can learn easier compare to those take more time to do the same. Delay has meaning and we explained the reasons.

Our future work will be on user modeling in serious games to complete our concept of adaptive learning. We are interested in serious games for applications in the field of learning languages.

\section{ACKNOWLEDGEMENT}

We are fully support by the Development Center for Research and Training of University of Human Development in Kurdistan Region of Iraq.

\section{REFERENCES}

[1] Aso Darwesh, Concepts of Serious Game In Education. International Journal of Engineering and Computer Science. Vol. 4 Issue 12, Page No. 15229-15232, December 2015.

[2] HAMDAOUI, Nabila, Mohammed KHALIDI IDRISSI, and Samir BENNANI. "Serious Games in Education Towards the standardization of the teaching-learning process." ADVANCES in EDUCATIONAL TECHNOLOGIES (2014): 174.

[3] Hendrix, M., Knutov, E., Auneau, L., Arnab, S., Dunwell, I., Petridis, P., Lameras, P. and de Freitas, S., 2013. Integrating serious games in adaptive hypermedia applications for personalised learning experiences.Vancouver

[4] El-Bakry, H.M., Saleh, A.A. and Asfour, T.T., 2011. A Novel Adaptive E-Learning Model Based on Developed Learner's Styles. World Academy of Science, Engineering and Technology, 60, pp.1946-1953. Vancouver

[5] Tremblay, Jonathan, Bruno Bouchard, and Abdenour Bouzouane. "Adaptive Game Mechanics for Learning PurposesMaking Serious Games Playable and Fun." CSEDU (2). 2010.

[6] Protopsaltis, A., Panzoli, D., Dunwell, I. and De Freitas, S., 2010. Repurposing serious games in health care education. In XII Mediterranean Conference on Medical and Biological Engineering and Computing 2010 (pp. 963-966). Springer Berlin Heidelberg.

[7] Juul, J., 2009. Fear of Failing? The Many Meanings of Difficulty in Video Games. The video game theory reader, 2, New York: Routledge, pp.237-252. 
[8] Annetta, L.A., Murray, M.R., Laird, S.G., Bohr, S.C. and Park, J.C., 2006. Serious games: Incorporating video games in the classroom. Educause quarterly, 29(3), p.16.

[9] Lindley, C.A. and Sennersten, C.C., 2006, December. Game play schemas: from player analysis to adaptive game mechanics. In Proceedings of the 2006 international conference on Game research and development (pp. 47-53). Murdoch University.

[10] Chen, J. 2006. Flow in games. MFA in Interactive Media, University of Southern California.

[11] Gilleade, K.M. and Dix, A., 2004, September. Using frustration in the design of adaptive videogames. In Proceedings of the 2004 ACM SIGCHI International Conference on Advances in computer entertainment technology (pp. 228-232). ACM.

[12] Hunicke, R., 2005, June. The case for dynamic difficulty adjustment in games. In Proceedings of the 2005 ACM SIGCHI
International Conference on Advances in computer entertainment technology (pp. 429-433). ACM.

[13] Paramythis and Reisinger. "Adaptive Learning Environments and e- Learning Standards". Electronic Journal of eLearning 2004. http://www.ejel.org/volume 2/vol2-issue1/issue1-art11paramythis.pdf. Retrieved 2010-03-13.

[14] Gilleade, K.M. and Dix, A., 2004, September. Using frustration in the design of adaptive videogames. In Proceedings of the 2004 ACM SIGCHI International Conference on Advances in computer entertainment technology(pp. 228-232). ACM.

[15] D.A. Kolb, Experiential learning: Experience as the source of learning and development. Prentice-Hall Englewood Cliffs. 1984.

[16] Amorim, R.R., Lama, M., Sánchez, E., Riera, A. and Vila, X.A., 2006. A learning design ontology based on the IMS specification. Educational Technology \& Society, 9(1), pp.38-57. 